\title{
SPACIAL DISTRIBUTION OF RISK AND RELIABILITY IN SLOPES
}

\author{
Vageesha S. Mathada ${ }^{1}$ \\ ${ }^{\text {I}}$ Professor, Civil Engineering, SVERI's College of Engineering, Pandharpur - 413 304, Maharashtra
}

\begin{abstract}
In conventional risk analysis, maximum probability of failure, $p_{f}$, obtained from reliability analysis is used to compute risk. There will be a single value of reliability index (or $p_{f}$ ) and hence a single value of risk (product of $p_{f}$ and cost of damage) for the entire slope. The assumption of cost of damage to be a constant leads to a single value of risk. Even the single value of reliability index does not provide any insight to the safety of the entire slope. More the volume of the slip mass more would be the cost of damage. Since the reliability index shows a flat minimum similar to factor of safety within the slope, chances of failure occurring near the vicinity of the minimum reliability surface cannot be completely ruled out. This implies that risk and reliability are no longer single values. In this paper an attempt is made to plot the safety and risk maps for a given slope. From the results it is clear that the maximum risk surfaces are different for different cost functions. The developed maps become practically useful to decide the extent of remedial measures.
\end{abstract}

Keywords: Risk, Reliability, Safety Map, Spatial Distribution, Slope stability

\section{INTRODUCTION}

Slope stability is one of the major problem in geotechnical engineering, as soil is a complex engineering material that has been formed by a combination of various geologic, environmental, and physio-chemical processes. Because of these natural processes, All soil properties at site will vary vertically and horizontally. A realistic assessment of slope reliability should consider the spatial variability of shear strength parameters (Beacher, G. B. and Christian, J. T. (2003)

Classical risk analysis for slopes seeks the minimum reliability index (or maximum probability of failure) and the associated cost of damage. Limit equilibrium analysis is used for reliability calculations. Usually a number of candidate slip surfaces are considered and the minimum reliability index of all the candidate slip surfaces is defined as the reliability index of the slope. The corresponding probability of failure is used to evaluate the risk. The extent and cost of damage are proportional to the volume of the slip mass. Usually the surface with the least reliability index is considered for the whole slope and the associated risk with that slip surface is reported as the risk for the entire slope. This may be mathematically convenient; however it limits the practical usefulness of the analysis. There could be slip surfaces with greater reliability index but with associated higher costs of damage leading to higher risk. The main objective of risk and reliability analysis is reduction of risk. Hence there is a need to investigate the spatial distribution of reliability and risk within the slope. A general framework for spatial distribution of reliability and risk is introduced in this paper. The results are presented in the form of risk and reliability maps. Mathada (2006) used different methods for assessing the stability of slopes. Baker and Leshchinsky (2001) used a similar approach to obtain the spatial distribution of factors of safety within the slope.

\section{RELIABILITY AND RISK}

Reliability computations account for uncertainties in the properties of soil. The computations make use of classical limit equilibrium methods for finding factor of safety and reliability is calculated as:

$$
R=\frac{\mu[F S]-1.0}{\sigma[F S]}
$$

Where, $\mu[\mathrm{FS}]=$ mean factor of safety, and $\sigma[\mathrm{FS}]$ is the standard deviation of factor of safety. Mean and standard deviation of factor of safety can be computed by many well known methods (Beacher and Christian, 2003). Here First Order Second Moment (FOSM) method has been used. Factor of safety is computed using Culmann's equation for plane slip surface.

Risk can be defined as:

$$
\text { Risk }=p_{f} \times \text { Cost of damage due to failure }
$$

Where $p_{f}$ is the probability of failure.

Usually the cost due to failure is assumed as constant resulting in a single value of risk for a slope. Basically, slip can occur through different failure surfaces and the cost of damage is proportional to the volume of slipped mass, if the failure is not catastrophic. As the slip surface changes, its $\mathrm{p}_{\mathrm{f}}$, the associated slip mass and the risk also change. Here the risk is the product of $p_{f}$ and the cost due to damage associated slip mass in 
consideration. The following three cost functions were chosen for assessing the damage due to failure for comparison. They are

$$
\begin{aligned}
& C_{1}=W \\
& C_{2}=W^{2} \\
& C_{3}=e^{W}
\end{aligned}
$$

Where $\mathrm{W}$ is the weight of the slip mass in $\mathrm{MN}$.

\section{SAFETY AND RISK MAPS}

It is required to evaluate safety (or reliability) at several points within the slope for the preparation of safety maps. Similarly, risk at all these points in the slope is required for the preparation of risk map. Consider the slope shown in Fig. 1. If it is required to calculate the safety (or risk) at any point $\mathrm{D}$ in the slope, one needs to consider all possible slip surfaces passing through that point $\mathrm{D}$.

In the present case only planar surfaces are considered. A range of possible failure planes passing through $\mathrm{D}$ is considered with $\theta_{\min }$ as the angle made by the plane passing through $\mathrm{D}$ and $\mathrm{C}$, and $\theta_{\max }$ as the angle made by the plane containing $\mathrm{D}$ and $\mathrm{A}$. It is assumed that the admissible $\theta$ is in the range of $\theta_{\min }$ and $\theta_{\max }$. The general expression for factor of safety given by Culmann (Taylor, 1948) for plane failure case can be simplified for any plane passing through $\mathrm{D}$ and having an angle $\theta$ with the horizontal as

$$
F(\theta)_{D}=\frac{2 c}{\gamma H} \frac{1}{\left(1-\frac{x_{D}\left[\tan \theta_{\max }-\tan \theta\right] \tan \beta}{\tan \beta-\tan \theta}\right)}\left(\frac{\sin \beta}{\sin \theta \sin (\beta-\theta)}\right)+\frac{\tan \phi}{\tan \theta}
$$

Equation (3) is used for computing partial differentials with respect to $c$ and $\phi$ and reliability index, $\operatorname{RI}(\theta)_{\mathrm{D}}$ is calculated using

$$
R I(\theta)_{D}=\frac{\mu\left[F(\theta)_{D}\right]-1.0}{\sigma\left[F(\theta)_{D}\right]}
$$

Reliability index at $\mathrm{D}$ is given by $\min \left\{\left[R I(\theta)_{D}\right] ; \theta_{\min } \leq \theta \leq \theta_{\max }\right\}$. Similarly, risk at $\mathrm{D}$ is given by $\max \left\{\left[\operatorname{Risk}(\theta)_{D}\right] ; \theta_{\min } \leq \theta \leq \theta_{\max }\right\}$

Classical search method coupled with root finding routine is used to get the points of required value of the function in the slope. The safety and risk maps are prepared by drawing contours of equal reliability index in case of safety map, and equal risk in case of risk maps.

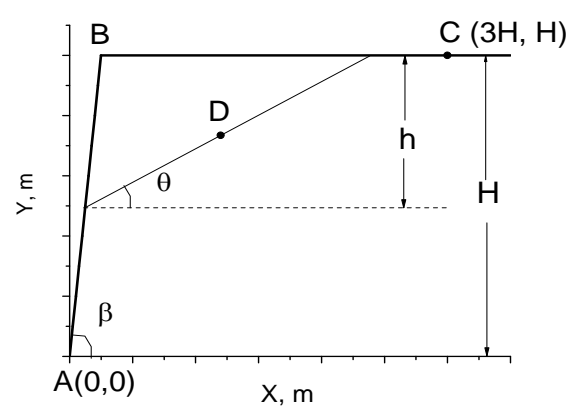

Fig. 1 Planar Slip Surface in Slopes

Table 1 Properties of the slope

\begin{tabular}{|c|l|}
\hline Parameter & \multicolumn{1}{|c|}{ Description of the parameter } \\
\hline Height, $\mathrm{H}$ & Deterministic, $10 \mathrm{~m}$ \\
\hline Slope angle, $\theta$ & Deterministic, $76^{\circ}$ \\
\hline Unit Weight, $\gamma$ & Deterministic, $20 \mathrm{kN} / \mathrm{m}^{3}$ \\
\hline Cohesion, c' & $\begin{array}{l}\text { Probabilistic, Mean }=30 \mathrm{kPa}, \\
\text { CoV=30\% }\end{array}$ \\
\hline $\begin{array}{c}\text { Angle of shearing } \\
\text { resistance, } \phi\end{array}$ & $\begin{array}{l}\text { Probabilistic, Mean }=30^{\circ}, \\
\mathrm{CoV}_{\tan \phi}=30 \%\end{array}$ \\
\hline
\end{tabular}

\section{AN ILLUSTRATION:}

A simple homogeneous slope as shown in Fig. 1 with the properties as mentioned in Table 1 is considered for illustration.

The procedure explained in the previous section is used to evaluate reliability and risk at every point in the slope. The resulting safety map is shown in Fig. 2 and the risk map for cost function $\mathrm{C} 1$ in Fig. 3. Fig. 4 shows the minimum reliability surface, min factor of safety surface- and the maximum risk surfaces for all the three cost functions.

\section{RESULTS AND DISCUSSION}

From Fig. 4 it is clear that minimum reliability and minimum factor of safety surfaces do not coincide. It is also clear that the maximum risk surfaces vary with the cost functions. Fig. 2 gives the complete idea of safety of the entire slope as against a single value in classical reliability method. This may be helpful in determining the extent of support (or remedial) measures required to achieve the desired reliability. 


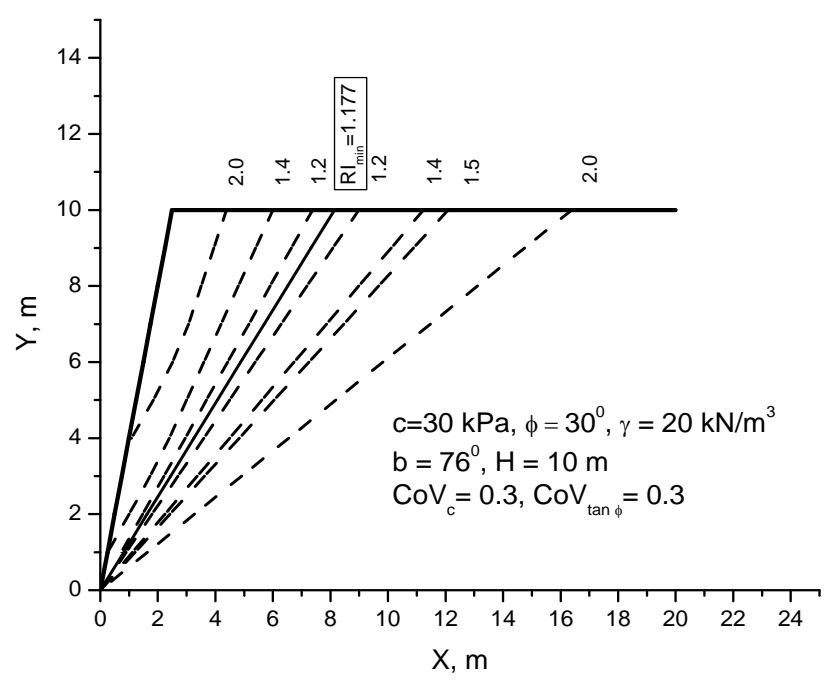

Fig. 2 Safety Map showing the distribution of Reliability Index

Fig. 3 is useful to mark risk zones of different risk ranges within the slope. Fig. 5 shows the variation of risks and $p_{\mathrm{f}}$ on the top surface of the slope. The present analysis is restricted to plane failure surfaces purely for demonstration of the concept. It can be extended to more realistic situations.

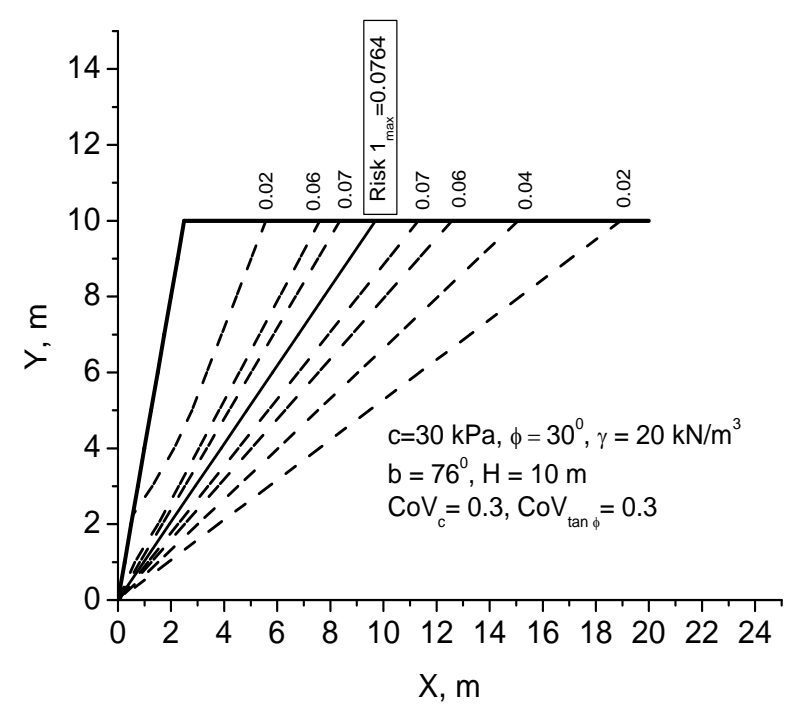

Fig. 3 Risk Map showing the distribution of Risk for Cost function $\mathrm{C}_{1}$

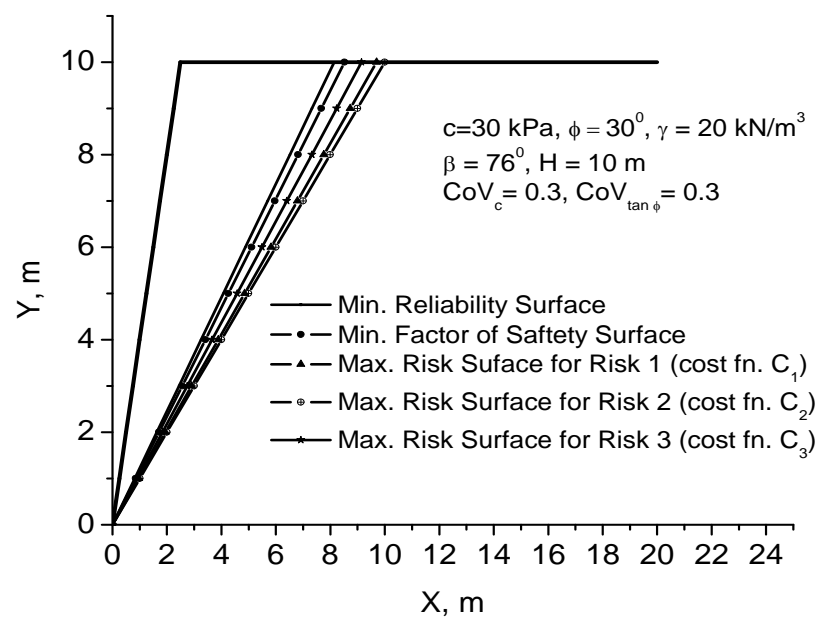

Fig. 4 Figure showing different surfaces

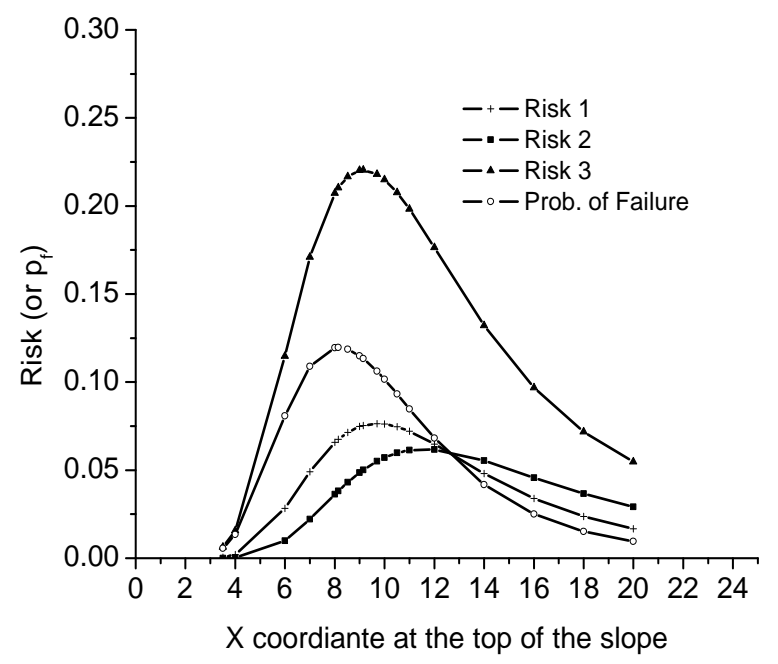

Fig. 5 Variation of risks and $p_{f}$ on the top of the slope surface

\section{CONCLUSIONS}

1. The minimum reliability and minimum factor of safety surfaces are different as may be expected.

2. The position of the maximum risk surface changes with the cost function assumed.

3. Safety maps provide an insight into the state of stability within the slope than to a single value obtained in the classical reliability analysis.

4. The extent of remedial measures, if warranted, can be easily fixed with the aid of either the safety map or risk map during reliability based design of slopes.

5. Risk map may be useful for the preparation of zonation map with different ranges of risk within the slope. 


\section{REFERENCES}

[1] Baker, R. and Leshchinsky, D. (2001), "Spatial Distribution of Safety Factors." J. Geotechnical and Geoenvironmental Engineering, ASCE, Vol. 127, pp. 135-145.

[2] Beacher, G. B. and Christian, J. T. (2003), Reliability and Statistics in Geotechnical Engineering, John Wiley\& Sons, England.

[3] Baecher GB, Christian JT. Spatial variability and geotechnical reliability. In: Phoon KK, editor. Reliability-based design in geotechnical engineering: computations and applications. London and New York: Taylor \& Francis; 2008. p. 76-133.

[4] Dian-Qing Li et.al. (2013) Effect of spatially variable shear strength parameters with linearly increasing mean trend on reliability of infinite slopes, Structural Safety xxx (2013) xxx-xxx, Paper in press.

[5] Mathada, V., S., (2006), Fuzzy, Fuzzy-Random and Hybrid Reliability Analysis of Earth Slopes, and RBD of Earth Walls, Ph.D. Dissertation, Indian Institute of Technology Bombay, Mumbai.

[6] Mathada, V.S., Venkatachalam, G., Srividya, A. 'Slope Stability Assessment - A Comparison of Probabilistic, Possibilistic and Hybrid Approaches', International Journal of Performability Engineering. July 2007; 3(3): 355-368. [22]

[7] Press, W. H., Teukolsky, S. A., Vetterling, W. T. and Flannery, B. P. (1994). Numerical Recipes in FORTRAN, Second Edition, Cambridge University Press, Cambridge.

[8] Taylor, D. W. (1948). Fundamentals of Soil Mechanics, Wiley, New York. 